\title{
Produtividade energética da madeira de Tachigali vulgaris por classe diamétrica em plantios experimentais na Amazônia
}

\author{
Bruna Bárbara Maciel Amoras ORELLANA ${ }^{1 *}$, Ailton Teixeira do Vale ${ }^{1}$, Joaquim GONÇALEZ ${ }^{1}$, \\ Marcelino Carneiro GUEDES ${ }^{2}$, Jorge Breno Palheta ORELLANA ${ }^{3}$, Clarissa Melo LIMA ${ }^{4}$
}

${ }^{1}$ Programa de Pós-Graduação em Ciências Florestais, Universidade de Brasília, Brasília, DF, Brasil. ${ }^{2}$ Centro de Pesquisa Agroflorestal do Amapá, Empresa Brasileira de Pesquisa Agropecuária, Macapá, AP, Brasil. ${ }^{3}$ Mestrado em Ciências Florestais, Departamento de Engenharia Florestal, Universidade de Brasília, Brasília, DF, Brasil. ${ }^{4}$ Departamento de Administração, Universidade de Brasília, Brasília, DF, Brasil. *E-mail: bruna.amoras@gmail.com

Recebido em junho/2017; Aceito em julho/2018.

\begin{abstract}
RESUMO: Este artigo visa analisar a produtividade energética de dois plantios experimentais de Tachigali vulgaris no Amapá, em ecossistemas e idades distintos, a partir da diferença de classes diamétricas. Foram coletadas 21 árvores (por plantio) distribuídas em 7 classes de diâmetro. Coletaram-se amostras de seções transversais do tronco para analisar a umidade máxima e densidade básica em diferentes posições axiais (base, meio e topo). O poder calorífico superior, densidade energética, materiais voláteis, teor de cinzas e biomassa seca foram analisados por classe diamétrica. Os dados foram avaliados por meio de análise de variância, teste de médias e relações lineares. A média da densidade básica nos plantios foi $581 \mathrm{~kg} / \mathrm{m}^{3}$ (cerrado) e $562 \mathrm{~kg} / \mathrm{m}^{3}$ (terrafirme). Houve efeito significativo na posição axial apenas no plantio de terra-firme. Somente neste ambiente não houve diferença significativa em materiais voláteis e PCS. No cerrado, a produtividade energética foi superior à terra-firme em todas as classes, devido à diferença de idade e ausência de competição. Em ambos os plantios a produtividade energética foi maior no diâmetro de 22 a $25 \mathrm{~cm}$ (classe 4), indicando ser esta a classe diamétrica ideal para colheita da madeira quando o objetivo for o manejo para bioenergia.
\end{abstract}

Palavras-chave: florestas energéticas, biomassa, Tachigali vulgaris, madeira.

\section{Energetic density of Tachigali vulgaris wood by diametric class in two experimental plants in the Amazon}

\begin{abstract}
This paper aims to analyze the energy productivity of two experimental Tachigali vulgaris plantations in Amapá, in distinct ecosystems and ages, from the difference of diametric classes. 21 trees (by planting) were collected in 7 diameter classes. Samples of cross-sections of the trunk were collected to analyze the maximum moisture and basic density in different axial positions (base, middle and top). The higher heating value, energetic density, volatile materials, ash content and dry biomass were analyzed by diameter class. The data were evaluated through analysis of variance, test of means and linear relations. The means basic density of plantations was $581 \mathrm{~kg} / \mathrm{m}^{3}$ (cerrado) and $562 \mathrm{~kg} / \mathrm{m}^{3}$ (terra firme). There was a significant effect on the axial position only in the terra-firme planting. Only in this environment there was no significant difference in volatile materials and higher heating value. In the cerrado, the energy productivity was superior to the terra-firme in all the classes, due to the difference of age and absence of competition. In both plantations the energy productivity was higher in the diameter of 22 to $25 \mathrm{~cm}$ (class 4), indicating that this is the ideal diametric class for harvesting the wood when the objective is the management for bioenergy.
\end{abstract}

Keywords: energy forests, biomass, Tachigali vulgaris, wood.

\section{INTRODUÇÃO}

As florestas com fins energéticos, ou florestas energéticas, visam uma maior produção sustentável de biomassa por unidade de área e num menor espaço de tempo. Segundo Vidal; Hora (2011) uma vantagem do uso de florestas energéticas é a não obrigatoriedade de colher o produto anualmente. Outro diferencial é o múltiplo uso da madeira que possibilita ao produtor vender o produto ao mercado mais atraente, quando a logística permitir, maximizando sua rentabilidade.

Atualmente, no Brasil, no que concerne a povoamentos comerciais há predomínio do plantio de espécies gênero Eucalyptus e Pinus. Entretanto, a opção por espécies nativas pode significar uma alternativa mais vantajosa e adequada para pequenos produtores locais e plantios em menor escala, por exemplo, e não deve ser descartada.

O potencial das florestas energéticas depende em parte da produtividade da biomassa lenhosa das espécies plantadas, a partir de características da madeira, principalmente em termos de densidade e poder calorífico, dos métodos silviculturais aplicados e das habilidades de adaptação das espécies às diferentes condições na localização (PEREZ at al., 2014). Neste último aspecto, a adoção de espécies nativas ao invés de espécies exóticas confere larga vantagem, pois dispensa-se o período de adaptação. Melotto et al. (2009), afirmaram que a escolha adequada de espécies florestais nativas devem cumprir o objetivo do plantio e as exigências ecológicas regionais, garantindo retornos econômicos e ambientais satisfatórios. 
Em decorrência do aumento da demanda por lenha e carvão oriunda de florestas nativas na Amazônia oriental a partir de meados dos anos 70 e 80 , ocasionada principalmente pelo crescimento das atividades minerárias na região, a Embrapa tem desenvolvido pesquisas com espécies nativas e exóticas com potencial para produzir lenha e seus derivados.

Ainda assim, são escassas as informações sobre florestas energéticas com plantas nativas no Brasil. Costa et al. (2014) ressaltam que estudos com madeiras nativas são necessários para que se possam ter indicativos do potencial de uso dessas espécies para finalidades energéticas, direcionando, assim, avanços nas pesquisas de melhoramento genético.

Nesse sentido, Sousa et al. (2016) descrevem que o tachibranco (Tachigali vulgaris L. G. Silva \& H. C. Lima, antes Sclerolobium paniculatum), é uma espécie arbórea endêmica do Brasil com características desejáveis tanto para produção energético-madeireira. A madeira desta espécie possui alto poder calorífico, sendo amplamente usada para lenha, carvão e obras civis leves (OLIVEIRA et al., 2008).

Embora o eucalipto seja uma das espécies mais utilizadas no reflorestamento para produção de madeira, carvão vegetal e papel e celulose no Brasil, Farias et al. (2016) concluíram que o T. vulgaris tem potencial para substituir o eucalipto em plantações comerciais com o benefício adicional de ser uma espécie nativa que podem promover o estabelecimento de uma cobertura florestal estável em locais degradados.

Segundo Lima (2012), esta espécie ocorre naturalmente nas regiões Norte (Pará, Amazonas e Tocantins), Nordeste (Maranhão, Piauí, Ceará e Bahia), Centro-Oeste (Mato Grosso, Goiás, Distrito Federal e Mato Grosso do Sul) e Sudeste (São Paulo e Minas Gerais).

A estrutura de uma floresta plantada e de uma floresta nativa apresenta grandes diferenciações, o que pode ser interpretado por meio do padrão de distribuição de diâmetros. Dessa forma, por meio das diferenças no diâmetro pode-se estabelecer um intervalo ideal para abate das árvores que resultem em uma produção mais eficaz de biomassa para geração de energia. Da mesma forma, dentro da mesma árvore pode haver variações em umidade e densidade básica em estruturas distintas. Estes parâmetros podem ser influenciados, por exemplo, na base do tronco pelo sistema radicular e o topo pelas ramificações. Assim, mesmo quando o destino é a queima, torna-se importante verificar o desempenho de produção de energia ao longo do fuste.

Um dos parâmetros mais importantes para se analisar a viabilidade energética de uma espécie é a densidade energética, e está relacionada à energia contida num determinado volume de madeira. A produtividade energética por unidade de área permite uma melhor visualização do melhor planejamento dos empreendimentos que dependem da energia da biomassa florestal (LIMA et al., 2011).

Dessa forma, torna-se essencial a existência de experimentos florestais estabelecidos para que se permita a obtenção de novas informações referentes à qualificação de espécies destinadas à geração de energia e, por extensão, com vocação de formação de maciços florestais, destinados à produção de material dendroenergético (ELOY et al., 2015).

Além disso, analisar o comportamento de povoamentos de espécies nativas em diferentes ambientes naturais ajuda a compreender as características intrínsecas desses povoamentos no que diz respeito aos fatores ecológicos de acordo com o ecossistema em que se encontram.
Diante de questões importantes e complexas que compõem o contexto do planejamento da produção de madeira, tornamse indispensáveis as informações relacionadas à qualidade da madeira que será produzida em função dos sítios de crescimento, como uma ferramenta fundamental para a tomada de decisão (CASTELO et al., 2008).

Dentro desse contexto, o presente trabalho tem como objetivo analisar a produtividade energética da parte aérea das árvores de dois plantios de tachi-branco em diferentes ecossistemas no estado do Amapá.

\section{MATERIAL E MÉTODOS}

Visando otimizar o uso do tachi-branco por comunidades e empresas siderúrgicas, a Embrapa desenvolveu diversas pesquisas com plantios experimentais desta espécie no Amapá. Esses mesmos experimentos foram aproveitados para 0 desenvolvimento deste trabalho. Portanto, a coleta dos dados de campo foi realizada em duas áreas distintas: o Campo Experimental da Embrapa/Amapá no cerrado, município de Macapá-Amapá-Brasil; e uma propriedade particular localizada no assentamento Piquiazal, em região de floresta de transição, município de Mazagão-Amapá-Brasil.

O campo experimental do cerrado possui uma área de 1.327 ha e está situado a $44 \mathrm{~km}$ da capital Macapá. O clima predominante na área, segundo a classificação de Köppen, é Ami-Tropical chuvoso, com precipitação pluvial anual média de $2.260 \mathrm{~mm}$ concentrada entre os meses de janeiro a julho. Este campo experimental do cerrado possui 3 plantios de $T$. vulgaris, o escolhido ocupa uma área de $6.125 \mathrm{~m}^{2}$, foi plantado com espaçamento de $3,0 \times 2,5 \mathrm{~m}$ e possuía 20 anos no momento da coleta.

O outro plantio estudado está localizado em um projeto de assentamento (PA) na comunidade do Piquiazal, localizada a 65 km da capital Macapá, no município de Mazagão, região sul do Amapá. Essa área encontra-se em ambiente de floresta de terra-firme, assim denominada por estar situada em relevo mais alto, onde não há alagamentos, o que justifica a nomenclatura adotada para diferenciar as áreas estudadas neste trabalho. A Figura 1 apresenta um mapa com a localização dos plantios estudados e a distância entre eles em linha reta.

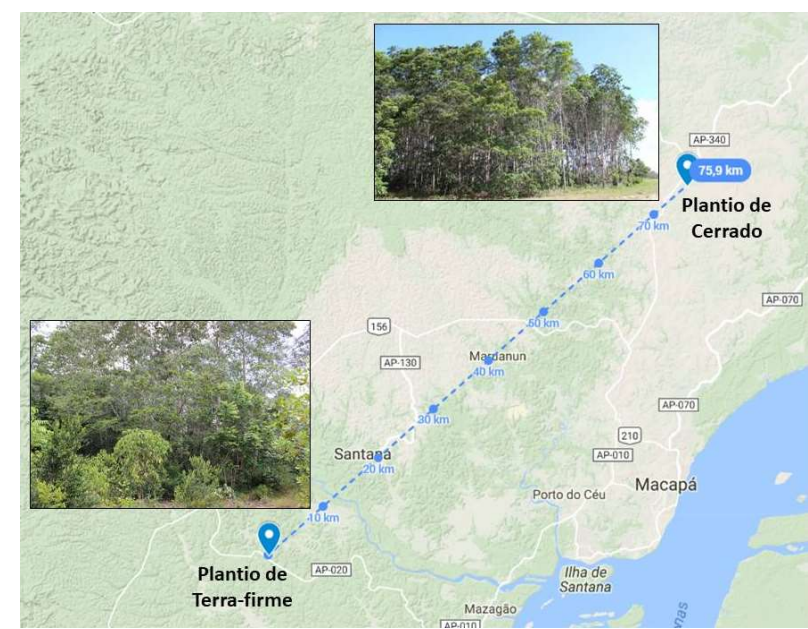

Figura 1. Mapa de localização dos plantios experimentais. Fonte: Google Maps.

Figure 1. Location map of experimental plantations. Source: Google Maps.

Em um dos lotes deste assentamento foi realizado um plantio de T. vulgaris em consórcio com Acacia mangium, que 
possui características de crescimentos semelhantes ao primeiro. Este plantio estava com 15 anos no momento da coleta, foi plantado em espaçamento $3 \mathrm{~m} \mathrm{x} 3 \mathrm{~m}$ em uma área de $3897 \mathrm{~m}^{2}$.

A Tabela 1 a seguir apresenta a síntese das características de cada plantio escolhido e as condições naturais das áreas em que se encontram.

Tabela 1. Caracterização dos plantios experimentais estudados. Table 1. Characterization of experimentais plantations studied.

\begin{tabular}{|c|c|c|}
\hline & Cerrado & Floresta terra-firme \\
\hline Área & $6.125 \mathrm{~m}^{2}$ & $3.897 \mathrm{~m}^{2}$ \\
\hline Espaçamento & $3 \mathrm{~m} \times 2,5 \mathrm{~m}$ & $3 \mathrm{~m} \times 3 \mathrm{~m}$ \\
\hline Idade & 20 anos & 15 anos \\
\hline Ecossistema & $\begin{array}{l}\text { Campo cerrado e } \\
\text { cerrado stricto senso }\end{array}$ & Floresta de transição \\
\hline Solo & Latossolo amarelo & Latossolo amarelo \\
\hline $\begin{array}{l}\text { Temperatura } \\
\text { média anual }\end{array}$ & $26,7^{\circ} \mathrm{C}$ & $27,3^{\circ} \mathrm{C}$ \\
\hline Precipitação & $2.260 \mathrm{~mm}$ & $2.250 \mathrm{~mm}$ \\
\hline
\end{tabular}

Os dois plantios tiveram todos os indivíduos vivos inventariados a fim de obter o cálculo da produção por hectare. Foram obtidas medidas de diâmetro à altura do peito (DAP), medido a 1,30 $\mathrm{m}$ do solo, de todas as árvores vivas e a altura e massa apenas das árvores abatidas. As árvores foram distribuídas em classes de diâmetro conforme Scolforo; Melo (2006), que afirmaram que em povoamentos florestais o intervalo da classe diamétrica pode ficar compreendido entre 2 e $5 \mathrm{~cm}$.

Assim, chegou-se ao número de 7 classes diamétricas (Tabela 2). Após classificadas, foram sorteadas ao acaso três árvores de cada classe para serem abatidas, totalizando 21 árvores de cada plantio e 42 árvores no total do experimento.

Tabela 2. Classificação diamétrica das árvores dos plantios.

Table 2. Diametric classification of plantation trees.

\begin{tabular}{ccc}
\hline & $\begin{array}{c}\text { TERRA-FIRME } \\
15 \text { anos }\end{array}$ & $\begin{array}{c}\text { CERRADO } \\
20 \text { anos }\end{array}$ \\
\hline Classe & $\begin{array}{c}\text { Intervalo de diâmetro } \\
(\mathrm{cm})\end{array}$ & $\begin{array}{c}\text { Intervalo de diâmetro } \\
(\mathrm{cm})\end{array}$ \\
\hline 1 & $10-13,9$ & $10,2-14,3$ \\
2 & $14-17,9$ & $14,4-18,5$ \\
3 & $18-21,9$ & $18,6-22,7$ \\
4 & $22-25,9$ & $22,7-26,9$ \\
5 & $26-29,9$ & $27,0-31,1$ \\
6 & $30-33,9$ & $31,2-35,3$ \\
7 & $34-37$. & $35,4-39,5$ \\
\hline
\end{tabular}

Foram coletados discos diamétricos com aproximadamente $2,50 \mathrm{~cm}$ de espessura, em três posições axiais na altura do tronco, correspondendo à base, meio e topo (Figura 3).

Retirou-se de cada disco duas cunhas opostas, que foram submersas em água para saturação até massa constante, obtendo-se a massa saturada em balança de precisão com sensibilidade de $10^{-2} \mathrm{~g}$. Em seguida, as cunhas foram colocadas para secar, a $103 \pm 2^{\circ} \mathrm{C}$,em estufa, com circulação forçada de ar, modelo MA 035, até massa constante, obtendo a massa seca a $0 \%$ de umidade.

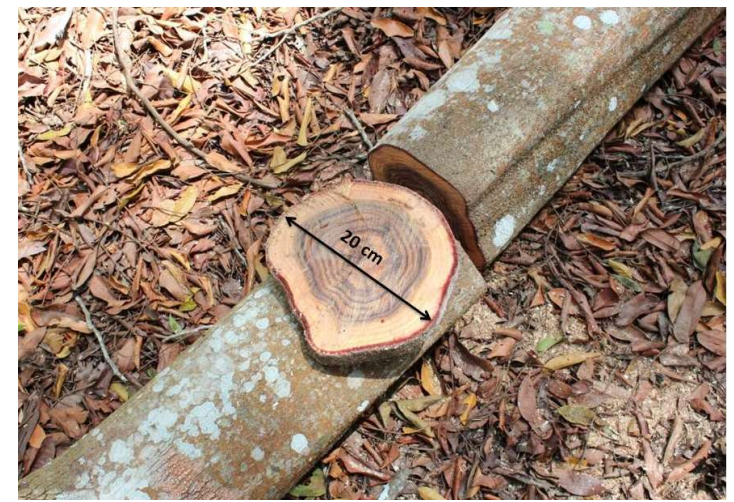

Figura 2. Coleta de discos por posição axial do tronco.

Figure 2. Collection of discs by axial position of the trunk.

A massa seca da madeira foi estimada conforme a Equação 01 , onde $\mathrm{M}_{0 \% \mathrm{C}}$ - massa seca de campo a $0 \%$ de umidade, $\mathrm{M}_{0 \% \mathrm{~A}}$ - massa seca da amostra a $0 \%$ de umidade e $\mathrm{M}_{\mathrm{UA}}$ - massa úmida da amostra.

$$
M_{0 \% C}=M_{U C}\left(\frac{M_{0 \% A}}{M_{U A}}\right)
$$

(Equação 01)

A biomassa seca por hectare foi calculada de acordo com a Equação 02, em que $B m$ - massa seca produzida por hectare $(\mathrm{kg} / \mathrm{ha}), M s$ - massa seca produzida por árvore $(\mathrm{kg}), F-$ frequência absoluta de árvores em cada classe diamétrica, $F t$ frequência total de árvores no plantio, $E$ - espaçamento do plantio $\left(\mathrm{m}^{2}\right)$.

$$
B m=M s x\left(\frac{F \times 10.000}{F t \times E}\right) \quad \text { (Equação 02) }
$$

Com os dados de massa úmida e seca foi possível determinar a densidade básica pelo método do máximo teor de umidade (MTU) e umidade máxima segundo a NBR 7190 (ABNT, 1997), conforme Equações 03 e 04para cada posição axial e classe diamétrica.

$$
\begin{aligned}
& \rho_{b}=\frac{1}{\frac{M_{s a t}}{M_{0 \%}}-0,346} \\
& T U=\frac{M_{s a t}-M_{0 \%}}{M_{0 \%}} \times 100
\end{aligned}
$$

(Equação 03)

(Equação 04)

em que $\mathrm{M}_{0 \%}$ - massa seca, $\rho_{\mathrm{b}}$ - densidade básica, $\mathrm{M}_{\mathrm{SAT}}$ - massa saturada, TU - teor de umidade em base seca.

O material que sobrou dos discos foi moído em moinho de facas e, em seguida, colocado em agitador por 3 minutos, obtendo-se partículas entre 40 e 60 mesh, para ensaio de materiais voláteis e fração abaixo de 60 mesh, para cinzas e poder calorífico. O poder calorífico da biomassa foi determinado com a utilização de uma bomba calorimétrica, conforme a norma NBR 8633 (ABNT, 1984). A execução dos ensaios de voláteis e cinzas ocorreu conforme os procedimentos descritos na norma NBR 8112 (ABNT, 1986), assim como a determinação do teor de carbono fixo. Esses parâmetros foram analisados apenas por classe diamétrica.

A densidade energética por árvore foi obtida conforme a equação 05 . 


$$
D e=D b \times P C S
$$

(Equação 05)

em que: $D e$ é a densidade energética $\left(\mathrm{kcal} / \mathrm{m}^{-3}\right) ; D b$ é a densidade básica $\left(\mathrm{g} / \mathrm{cm}^{-3}\right) ; P C S$ é o poder calorífico superior ( $\mathrm{kcal} / \mathrm{kg})$.

A produção energética foi calculada por meio do produto entre a biomassa seca produzida por árvore e o seu respectivo poder calorífico superior. A produtividade energética dos plantios foi resultado do produto do número de árvores por hectare pela produção energética. Já a produtividade energética por hectare anual levou em consideração a idade de cada plantio.

O delineamento estatístico utilizado foi inteiramente casualizado. Para análise dos dados foi realizada uma análise de variância fatorial para analisar as médias entre as classes e posições axiais e a uma análise de variância simples para verificar se existe diferença significativa entre as classes diamétricas em cada plantio. Em caso de pelo menos uma diferença significativa foi aplicado um teste de Tukey visando identificar diferenças entre as médias obtidas.

Realizaram-se análises de regressão linear para verificar os efeitos da densidade básica em relação ao diâmetro e à densidade energética.

\section{RESULTADOS}

$\mathrm{Na}$ Tabela 3 consta a produção média de biomassa seca por árvore e por hectare, em cada classe diamétrica nos dois plantios. A Tabela 4 apresenta os valores de "F" das análises de variância para os efeitos de classe, de posição axial (base, meio e topo) e da interação entre estes para umidade máxima e densidade básica.

Tabela 3. Médias de produção de biomassa seca de madeira no fuste por classe diamétrica produzida por árvore e por hectare.

Table 3. Means of dry biomass production of wood in the shaft by diameter class produced by tree and by hectare.

\begin{tabular}{ccccc}
\hline & \multicolumn{2}{c}{ CERRADO } & \multicolumn{2}{c}{ TERRA-FIRME } \\
\hline $\begin{array}{c}\text { Classe } \\
\text { diamétrica* }\end{array}$ & $\begin{array}{c}\mathrm{kg} / \\
\text { árvore }\end{array}$ & $\begin{array}{c}\mathrm{kg} / \\
\text { hectare }\end{array}$ & $\begin{array}{c}\mathrm{kg} / \\
\text { árvore }\end{array}$ & $\begin{array}{c}\mathrm{kg} / \\
\text { hectare }\end{array}$ \\
\hline $1(12,1)$ & 35,65 & 5.704 & 25,82 & 2.917 \\
$2(16,2)$ & 100,35 & 16.858 & 54,77 & 6.901 \\
$3(20,3)$ & 162,32 & 26.783 & 86,48 & 10.205 \\
$4(24,4)$ & 211,19 & 33.369 & 158,82 & 12.705 \\
$5(28,5)$ & 244,69 & 29.118 & 193,18 & 94.66 \\
$6(32,6)$ & 312,88 & 16.270 & 174,31 & 4.009 \\
$7(37,2)$ & 422,43 & 19.854 & 354,29 & 3.543 \\
\hline
\end{tabular}

*Os valores entre parênteses correspondem à médias de diâmetro de cada classe.

Em todos os casos, tanto para terra-firme quanto para o cerrado, o efeito da interação entre classe diamétrica e posição axial foi não significativo. Entretanto, foram constatadas diferenças significativas $(p<0,01)$ na umidade máxima e na densidade básica entre as classes diamétricas nos dois plantios. Quanto a posição axial, houve diferença entre as médias apenas no plantio de terra-firme.Nas Figuras 3 e 4 é possível observar o comportamento das médias da densidade básica e umidade máxima por posição axial.

A distribuição da umidade, ao longo do fuste na área de floresta de terra-firme, apresentou amplitude de $95 \%$ a $137 \%$, enquanto na área de cerrado a amplitude foi de $81 \%$ a $126 \%$.Essa diferença entre os plantios pode ser resultado da influência das características climáticas locais, onde o ambiente de terra-firme possui microclima mais úmido que o cerrado. Além disso, a densidade básica é inversamente proporcional ao teor de umidade, o que pode também ter contribuído para amplitude da umidade ter sido maior no plantio de terra-firme. A Tabela 5 apresenta as médias de umidade máxima e densidade básica, por classe diamétrica da madeira, no plantio da terra-firme e do cerrado e os respectivos desvios-padrões e teste de Tukey.

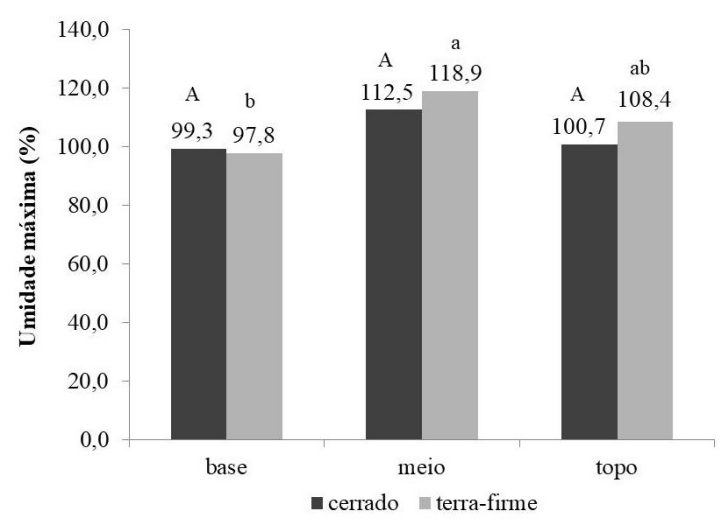

Figura 3. Umidade máxima por posição axial do tronco.

Figure 3. Maximum moisture per axial position of the trunk.

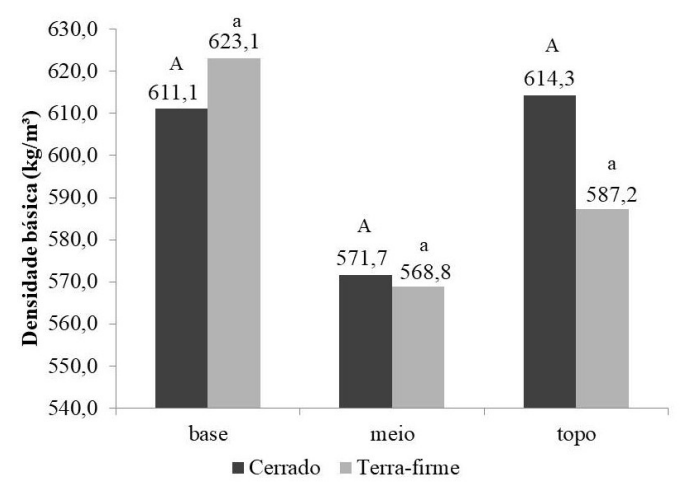

Figura 4. Densidade básica por posição axial do tronco. Figure 4. Basic density per axial position of the trunk.

Tabela 4. Valores de "F" para umidade máxima e densidade básica nos plantios de terra-firme e cerrado por classe de diâmetro e por posição axial do tronco.

Table 4. "F" values for maximum moisture and basic density in terrafirme planting by diametric class and axial position.

\begin{tabular}{|c|c|c|c|}
\hline \multicolumn{4}{|c|}{ TERRA-FIRME } \\
\hline \multirow{2}{*}{ FV } & \multirow{2}{*}{ GL } & \multicolumn{2}{|c|}{ Valores de F } \\
\hline & & Umáx (\%) & $\mathrm{Db}\left(\mathrm{kg} / \mathrm{m}^{3}\right)$ \\
\hline Classe diamétrica & 6 & $3,54^{*}$ & $3,57^{*}$ \\
\hline Posição axial & 2 & $2,49^{*}$ & $1,13 \mathrm{~ns}$ \\
\hline $\mathrm{C} \times \mathrm{Pa}$ & 12 & $0,40 \mathrm{~ns}$ & $1,25 \mathrm{~ns}$ \\
\hline Erro & 42 & & \\
\hline $\mathrm{CVe}$ & & 12,75 & 7,85 \\
\hline \multicolumn{4}{|c|}{ CERRADO } \\
\hline \multirow{2}{*}{$\mathrm{FV}$} & \multirow{2}{*}{ GL } & \multicolumn{2}{|c|}{ Valores de $\mathrm{F}$} \\
\hline & & Umáx (\%) & $\mathrm{Db}\left(\mathrm{kg} / \mathrm{m}^{3}\right)$ \\
\hline Classe diamétrica & 6 & $4,73 * *$ & $5,53 * *$ \\
\hline Posição axial & 2 & $1,46 \mathrm{~ns}$ & $2,28 \mathrm{~ns}$ \\
\hline $\mathrm{C} \times \mathrm{Pa}$ & 12 & $0,99 \mathrm{~ns}$ & $0,98 \mathrm{~ns}$ \\
\hline Erro & 42 & & \\
\hline $\mathrm{CVe}$ & & 15,38 & 9,42 \\
\hline
\end{tabular}

** significativo ao nível de $1 \%$ de probabilidade $(\mathrm{p}<0,01)$

* significativo ao nível de $5 \%$ de probabilidade $(0,01=<\mathrm{p}<0,05)$ ns não significativo $(\mathrm{p}>=0,05)$ 
Tabela 5. Médias de umidade máxima (Umáx) e densidade básica $(\mathrm{Db})$ por classe, na madeira de tachi-branco em plantios de terra-firme e cerrado.

Table 5. Mean of maximum moisture (Umáx) and basic density (Db) per class, in tachi-branco wood in terra firme and cerrado plantations.

\begin{tabular}{ccccc}
\hline \multirow{2}{*}{$\begin{array}{c}\text { Classe } \\
\text { diamétrica }\end{array}$} & \multicolumn{2}{c}{ TERRA-FIRME } & \multicolumn{2}{c}{ CERRADO } \\
\cline { 2 - 5 } & $\begin{array}{c}\text { Db } \\
\left(\mathrm{kg} \cdot \mathrm{m}^{-3}\right)\end{array}$ & $\begin{array}{c}\text { Umáx } \\
(\%)\end{array}$ & $\begin{array}{c}\text { Db } \\
\left(\mathrm{kg} \cdot \mathrm{m}^{-3}\right)\end{array}$ & $\begin{array}{c}\text { Umáx } \\
(\%)\end{array}$ \\
\hline \multirow{2}{*}{$1(12,1)$} & $496 \mathrm{c}$ & $137 \mathrm{a}$ & $532 \mathrm{c}$ & $126 \mathrm{a}$ \\
& $(34,2)$ & $(14,2)$ & $(67,2)$ & $(24,2)$ \\
\hline \multirow{2}{*}{$2(16,2)$} & $551 \mathrm{bc}$ & $118 \mathrm{ab}$ & $576 \mathrm{bc}$ & $111 \mathrm{ab}$ \\
& $(56,5)$ & $(19,1)$ & $(72,9)$ & $(25,5)$ \\
\hline \multirow{2}{*}{$3(20,3)$} & $556 \mathrm{abc}$ & $116 \mathrm{ab}$ & $695 \mathrm{a}$ & $81 \mathrm{c}$ \\
& $(53,5)$ & $(17,7)$ & $(95,9)$ & $(19,0)$ \\
\hline \multirow{2}{*}{$4(24,4)$} & $586 \mathrm{ab}$ & $108 \mathrm{~b}$ & $571 \mathrm{bc}$ & $111 \mathrm{ab}$ \\
& $(68,7)$ & $(22,6)$ & $(48,1)$ & $(14,4)$ \\
\hline \multirow{2}{*}{$5(28,5)$} & $577 \mathrm{ab}$ & $108 \mathrm{~b}$ & $626 \mathrm{ab}$ & $95 \mathrm{bc}$ \\
& $(24,2)$ & $(7,2)$ & $(33,9)$ & $(8,9)$ \\
\hline \multirow{2}{*}{$6(32,6)$} & $630 \mathrm{a}$ & $95 \mathrm{~b}$ & $602 \mathrm{bc}$ & $\begin{array}{c}101 \mathrm{bc} \\
(3,7)\end{array}$ \\
& $(65,0)$ & $(17,0)$ & $(13,5)$ & $(3,7)$ \\
\multirow{2}{*}{$7(37,2)$} & $614 \mathrm{ab}$ & $98 \mathrm{~b}$ & $591 \mathrm{bc}$ & $105 \mathrm{abc}$ \\
& $(52,8)$ & $(13,6)$ & $(35,3)$ & $(10,0)$ \\
\hline
\end{tabular}

Médias seguidas por uma mesma letra, em cada coluna, não diferem estatisticamente (Tukey, $\mathrm{p}>0,05$ ).

No cerrado, as classes 3 e 5 apresentaram os maiores valores de densidade básica, enquanto em terra-firme foram as classes 6 e 7. Em ambas áreas, a classe 1 apresentou as menores densidades básicas. Os valores médios de densidade básica obtidos foram, respectivamente, $581 \mathrm{~kg} / \mathrm{m}^{3}$ e $562 \mathrm{~kg} / \mathrm{m}^{3}$, para cerrado e terra-firme.

Houve influência direta do diâmetro em relação à densidade básica, mais acentuadamente observada no plantio de Terra-firme. Observou-se que a medida que o diâmetro aumenta a densidade também tende a aumentar, conforme Figura 5.

Em relação aos parâmetros que remetem à caracterização energética da madeira analisada, no plantio de terra-firme houve diferença significativa apenas para cinzas e densidade energética entre as classes diamétricas. Na área de cerrado todos os parâmetros apresentaram diferenças significativas entre as classes de diâmetro (Tabela 6). A média do poder calorífico superior no plantio de terra-firme foi $4.539 \mathrm{kcal} / \mathrm{kg}$ e no plantio de cerrado $4.564 \mathrm{kcal} / \mathrm{kg}$. O teor médio de materiais voláteis foi semelhante entre os plantios, sendo $84,99 \%$ em terra-firme e $85,01 \%$ em cerrado, assim como em relação a teor de cinzas, onde se constatou média de $0,56 \%$ (terra-firme) e $0,59 \%$ (cerrado).

As médias dos parâmetros analisados na Tabela 6 estão expressas nas Tabelas 7 e 8 contendo os resultados dos agrupamentos realizados pelo teste Tukey nos casos em que se aplica.

A produtividade energética dos plantios está expressa em duas maneiras distintas. Na Figura 6 tem-se a produtividade de cada plantio por hectare em cada classe diamétrica, considerando a produtividade de indivíduos por hectare.

Na Figura 7 é possível analisar a produtividade energética anual por hectare em cada classe diamétrica, considerando que o plantio de terra-firme possuía 15 anos e o de cerrado 20 anos no período do estudo.
Tabela 6. Valores de "F" para materiais voláteis (MV), cinzas (CZ), poder calorífico superior (PCS) e densidade energética (DE) nos plantios de terra-firme e cerrado.

Table 6. The values of " $F$ " for volatile materials (MV), ashes (CZ), higher heating value (PCS) and energetic density (SD) in terra firme and cerrado.

\begin{tabular}{|c|c|c|c|c|c|}
\hline \multicolumn{6}{|c|}{ TERRA-FIRME } \\
\hline \multirow[b]{2}{*}{ FV } & \multirow[b]{2}{*}{ GL } & \multicolumn{4}{|c|}{ Valores de F } \\
\hline & & MV (\%) & \multirow{2}{*}{$\begin{array}{c}\mathrm{CZ} \\
(\%) \\
5,25^{* *}\end{array}$} & $\begin{array}{c}\mathrm{PCS} \\
(\mathrm{kcal} / \mathrm{kg})\end{array}$ & $\begin{array}{c}\mathrm{DE} \\
\left(\mathrm{Gcal} / \mathrm{m}^{3}\right)\end{array}$ \\
\hline Classe & 6 & $2,76 \mathrm{~ns}$ & & $0,35 \mathrm{~ns}$ & $4,72 * *$ \\
\hline Erro & 14 & & & & \\
\hline Total & 20 & & & & \\
\hline \multicolumn{6}{|c|}{ CERRADO } \\
\hline \multirow[b]{2}{*}{ FV } & \multirow[b]{2}{*}{ GL } & \multicolumn{4}{|c|}{ Valores de F } \\
\hline & & MV (\%) & $\begin{array}{l}\mathrm{CZ} \\
(\%)\end{array}$ & $\begin{array}{c}\text { PCS } \\
(\mathrm{kcal} / \mathrm{kg})\end{array}$ & $\begin{array}{c}\mathrm{DE} \\
\left(\mathrm{Gcal} / \mathrm{m}^{3}\right)\end{array}$ \\
\hline Classe & 6 & $4,08^{*}$ & $5,71 * *$ & $5,98^{* *}$ & $3,59^{*}$ \\
\hline Erro & 14 & & & & \\
\hline Total & 20 & & & & \\
\hline
\end{tabular}

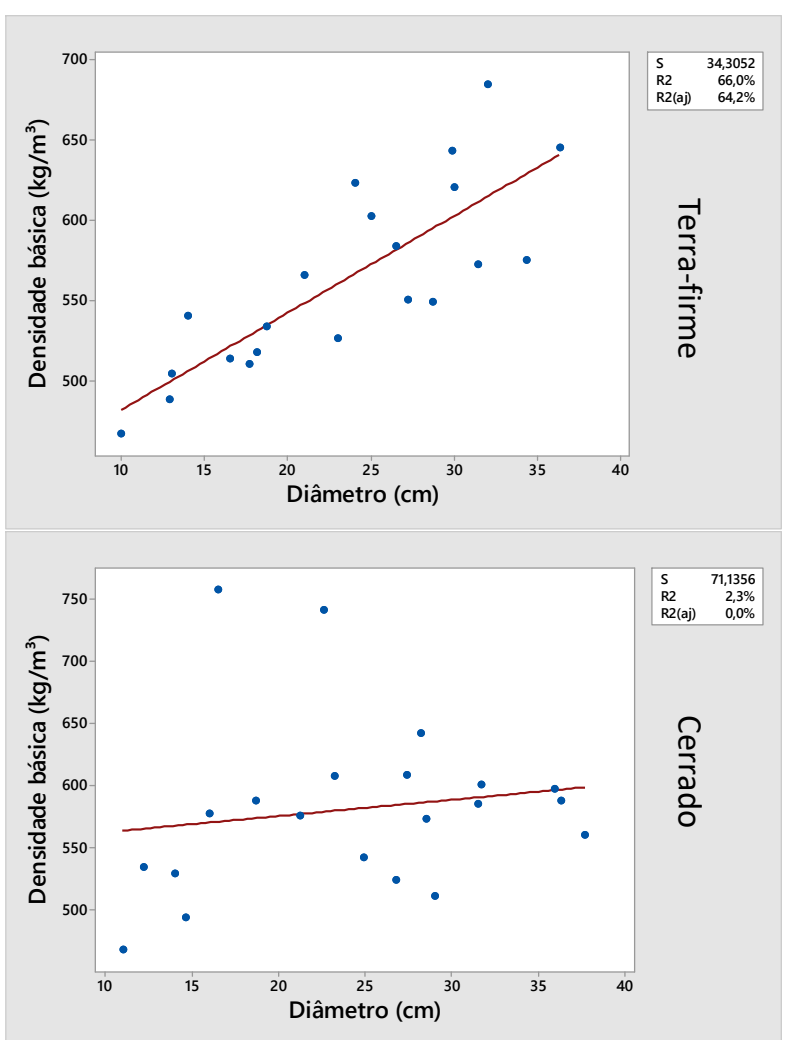

Figura 5. Comportamento da densidade básica a medida que o diâmetro aumenta nos plantios.

Figure 5. Behavior of basic density as the diameter increases in plantations.

A densidade energética não foi influenciada pelo poder calorífico superior devido à baixa variação do PCS entre as classes diamétricas, resultando em uma relação não significativa. Do mesmo modo, não houve relação significativa entre a biomassa seca produzida e a densidade energética. Por outro lado, a relação entre a densidade energética e densidade básica foi estatisticamente significativa, representado por uma equação linear com coeficiente de determinação de 0,88 no plantio de terra-firme e 0,99 no plantio de cerrado, como 
observa-se na Figura 8. Esta relação é esperada tendo em vista que a densidade básica é parâmetro para se determinar a densidade energética.

Tabela 7. Teste de Tukey para as médias de umidade máxima (Umáx), densidade básica (Db), materiais voláteis (MV), cinzas (CZ), poder calorífico superior (PCS) e densidade energética (DE) no plantio de terra-firme.

Table 7. Tukey's test for averages of maximum moisture (Umáx), basic density $(\mathrm{Db})$, volatile materials $(\mathrm{MV})$, ashes $(\mathrm{CZ})$, higher heating value (PCS) and energetic density (SD) in terra firme planting.

\begin{tabular}{ccccc}
\hline $\begin{array}{c}\text { Classe } \\
\text { diamétrica }\end{array}$ & $\begin{array}{c}\mathrm{MV} \\
(\%)\end{array}$ & $\begin{array}{c}\mathrm{CZ} \\
(\%)\end{array}$ & $\begin{array}{c}\mathrm{PCS} \\
(\mathrm{MJ} / \mathrm{kg})\end{array}$ & $\begin{array}{c}\mathrm{DE} \\
\left(\mathrm{GJ} / \mathrm{m}^{3}\right)\end{array}$ \\
\hline \multirow{2}{*}{ Classe 1} & $85,1 \mathrm{a}$ & $0,69 \mathrm{ab}$ & $19,09 \mathrm{a}$ & $9,27 \mathrm{~b}$ \\
& 0 & 0 & $-0,15$ & $-0,1$ \\
Classe 2 & $85,9 \mathrm{a}$ & $0,60 \mathrm{abc}$ & $19,02 \mathrm{a}$ & $9,90 \mathrm{~b}$ \\
& $-0,1$ & $-0,1$ & $-0,15$ & $-0,1$ \\
Classe 3 & $84,4 \mathrm{a}$ & $0,76 \mathrm{a}$ & $19,01 \mathrm{a}$ & $10,23 \mathrm{~b}$ \\
& $-0,1$ & $-0,2$ & $-0,13$ & $-0,1$ \\
Classe 4 & $85 \mathrm{a}$ & $0,47 \mathrm{bc}$ & $18,94 \mathrm{a}$ & $11,05 \mathrm{ab}$ \\
& $-0,1$ & $-0,1$ & $-0,13$ & $-0,2$ \\
Classe 5 & $85,3 \mathrm{a}$ & $0,49 \mathrm{abc}$ & $18,90 \mathrm{a}$ & $10,59 \mathrm{ab}$ \\
& 0 & $-0,1$ & $-0,14$ & $-0,1$ \\
Classe 6 & $84,3 \mathrm{a}$ & $0,42 \mathrm{c}$ & $18,98 \mathrm{a}$ & $13,14 \mathrm{a}$ \\
& 0 & $-0,1$ & $-0,14$ & $-0,5$ \\
Classe 7 & $84,7 \mathrm{a}$ & $0,48 \mathrm{bc}$ & $18,95 \mathrm{a}$ & $11,76 \mathrm{ab}$ \\
& $-0,2$ & $-0,1$ & $-0,13$ & $-0,2$ \\
\hline
\end{tabular}

Médias seguidas por uma mesma letra, em cada coluna, não diferem estatisticamente (Tukey, $\mathrm{p}>0,05$ ).

Tabela 8. Teste de Tukey para as médias de umidade máxima (Umáx), densidade básica (Db), materiais voláteis (MV), cinzas (CZ), poder calorífico superior (PCS) e densidade energética (DE) no plantio de cerrado.

Table 8. Tukey's test for averages of maximum moisture (Umáx), basic density $(\mathrm{Db})$, volatile materials $(\mathrm{MV})$, ashes $(\mathrm{CZ})$, higher heating value (PCS) and energetic density (SD) in cerrado planting.

\begin{tabular}{ccccc}
\hline $\begin{array}{c}\text { Classe } \\
\text { diamétrica }\end{array}$ & $\begin{array}{c}\mathrm{MV} \\
(\%)\end{array}$ & $\begin{array}{c}\mathrm{CZ} \\
(\%)\end{array}$ & $\begin{array}{c}\mathrm{PCS} \\
(\mathrm{MJ} / \mathrm{kg})\end{array}$ & $\begin{array}{c}\mathrm{DE} \\
\left(\mathrm{GJ} / \mathrm{m}^{3}\right)\end{array}$ \\
\hline \multirow{2}{*}{ Classe 1} & $84,4 \mathrm{~b}$ & $0,84 \mathrm{a}$ & $19,04 \mathrm{~b}$ & $9,71 \mathrm{~b}$ \\
& $-0,9$ & $-0,2$ & $-0,14$ & $-0,2$ \\
Classe 2 & $85,3 \mathrm{ab}$ & $0,66 \mathrm{ab}$ & $18,67 \mathrm{~b}$ & $10,41 \mathrm{~b}$ \\
& $-0,2$ & 0 & $-0,14$ & $-0,2$ \\
Classe 3 & $85 \mathrm{ab}$ & $0,59 \mathrm{~b}$ & $19,14 \mathrm{ab}$ & $13,31 \mathrm{a}$ \\
& $-0,2$ & 0 & $-0,14$ & $-0,4$ \\
Classe 4 & $85,1 \mathrm{ab}$ & $0,57 \mathrm{~b}$ & $19,11 \mathrm{~b}$ & $10,65 \mathrm{ab}$ \\
& $-0,2$ & 0 & $-0,13$ & $-0,2$ \\
Classe 5 & $84,7 \mathrm{ab}$ & $0,61 \mathrm{~b}$ & $19,09 \mathrm{a}$ & $11,20 \mathrm{ab}$ \\
& $-0,2$ & $-0,1$ & $-0,13$ & $-0,3$ \\
Classe 6 & 85,3 & $0,66 \mathrm{ab}$ & $19,28 \mathrm{~b}$ & $11,29 \mathrm{ab}$ \\
& $(0,3) \mathrm{a}$ & 0 & $-0,15$ & $-0,1$ \\
Classe 7 & $85,8 \mathrm{a}$ & $0,50 \mathrm{~b}$ & $19,00 \mathrm{ab}$ & $11,04 \mathrm{ab}$ \\
& $-0,4$ & 0 & $-0,15$ & $-0,1$ \\
\hline
\end{tabular}

Médias seguidas por uma mesma letra, em cada coluna, não diferem estatisticamente (Tukey, $\mathrm{p}>0,05$ ).

\section{DISCUSSÃO}

Na Tabela 3, constata-se que a produção de biomassa seca no fuste das árvores com maior diâmetro, ou seja, maiores classes diamétricas é superior. No entanto, analisando a produção por hectare, as classes 3, 4 e 5 foram superiores. Isso é explicado pelo número de indivíduos ser maior nestas classes, elevando a massa seca/ha em relação às classes maiores.

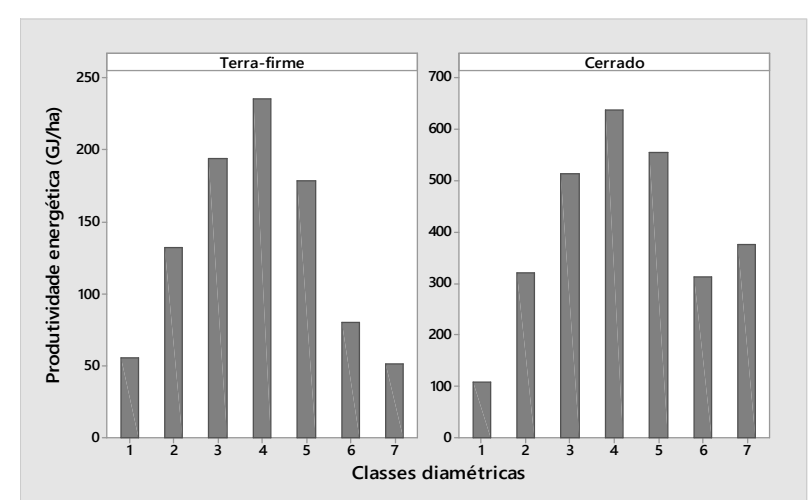

Figura 6. Densidade energética produzida por hectare nos plantios estudados.

Figure 6. Energetic density produced per hectare in the studied plantations.

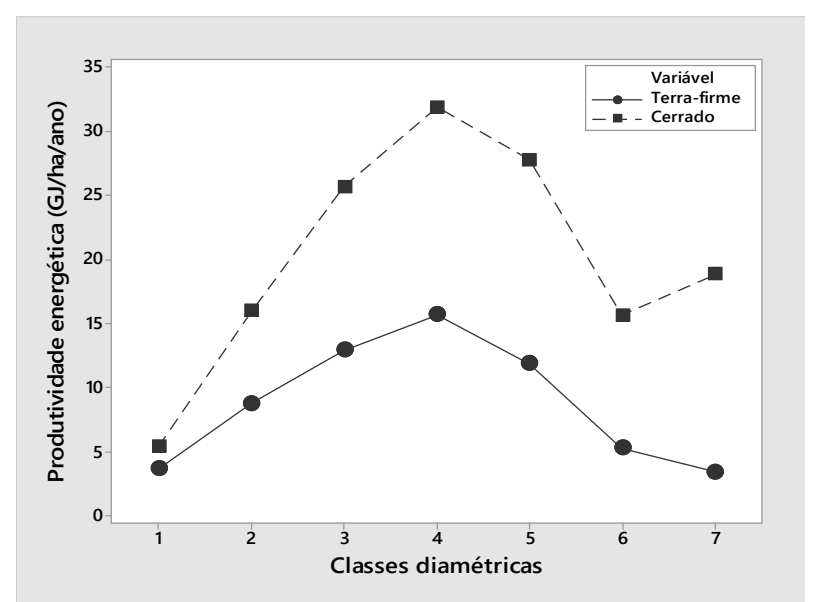

Figura 7. Densidade energética produzida por hectare/ano nos plantios estudados.

Figure 7. Energetic density produced per hectare/year in the studied plantations.

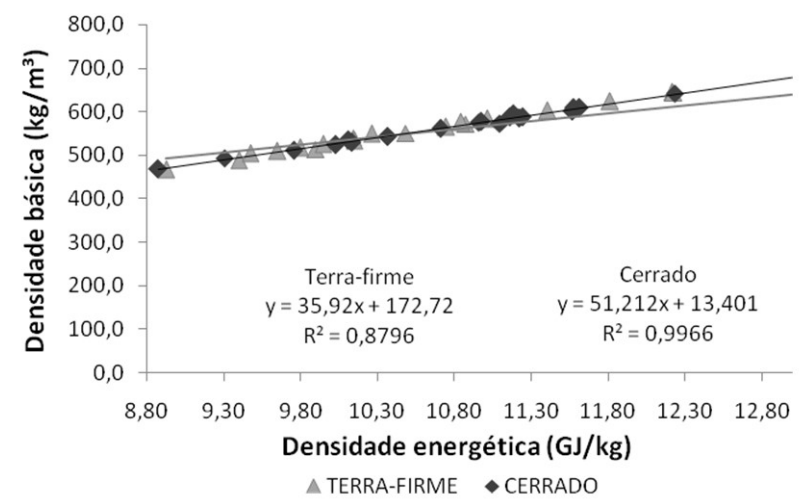

Figura 8. Relações lineares entre densidade básica e densidade energética nos plantios.

Figure 8. Linear relations between basic density and energetic density in the plantations.

Existe uma tendência de diminuição da umidade máxima com o aumento da densidade básica da madeira, como observou-se na Tabela 5. Este é um efeito esperado e se explica pelo fato de que madeiras com menores densidades possuem maior quantidade de espaços vazios e, por isto, comportam maior quantidade de água livre ou capilar, como cavidades celulares e espaços intercelulares, incluindo vasos e canais resiníferos, resultando em uma alta umidade das mesmas, conforme afirmam Zanuncio et al. (2013). 
Observa-se, também, uma tendência de aumento da densidade básica à medida que o diâmetro do tronco aumenta (classes diamétricas), principalmente no plantio de terra-firme, como consta na Figura 5. O tachi-branco apresenta o cerne distinto do alburno, enquanto o primeiro apresenta coloração marrom, o segundo apresenta coloração clara. Esta característica permite visualizar a proporção cerne/alburno no xilema. Apesar de apresentarem a mesma idade, as árvores de diferentes classes diamétricas apresentaram diferentes proporções cerne/alburno, o que pode explicar o aumento da densidade básica. Stallbaun et al. (2016) analisando pranchas de $T$. vulgaris verificaram que a distribuição do cerne e presença do lenho de tração podem interferir no comportamento da densidade. A distinção do efeito da classe diamétrica entre terra firme e cerrado pode estar associado a diferentes taxas de crescimento.

Observa-se ainda em relação à densidade básica que, apesar da diferença de idade, as médias apresentaram resultados aproximados, o que segundo Ribeiro et al. (2011) pode estar associado à diferença nos espaçamentos dos plantios e também em relação à disponibilidade de nutrientes do solo de cada localidade.

Com relação à posição axial, a base do tronco apresentou valores de densidade básica elevados nos dois plantios, diminuindo ao longo da altura e retomando valores maiores no topo, conforme Figura 4. O mesmo ocorreu com uma espécie similar, em termos de crescimento, a Acacia mangium, estudada por Gonçalves; Lelis (2012),em que constataram que a densidade básica apresentou uma diminuição ao longo do tronco até $75 \%$ da altura. A partir disso, a presença mais efetiva de galhos e ramos contribuiu para obtenção de maiores valores de densidade. $\mathrm{O}$ mesmo ocorre com o tachi-branco, pois como descreve Carvalho (2005), esta espécie apresenta dominância apical bem definida, do qual partem ramos não grossos, em ângulos abertos, formando copa estreita. Em decorrência desta característica, o autor recomenda que em espaçamentos mais largos seu plantio deve sofrer poda dos galhos.

As médias de densidade básica, encontradas neste trabalho, foram compatíveis com o obtido por Oliveira et al. (2008), ao analisar a madeira de tachi-branco em diferentes níveis de adubação no centro-oeste, onde encontraram valores de densidade básica na faixa de $520 \mathrm{~kg} / \mathrm{m}^{3}$. Já Thompson (2009) visando subsidiar a elaboração de técnicas para o uso sustentável do tachi-branco no cerrado stricto senso do centrooeste, obteve valores mais elevados para a madeira do fuste, variando de 690 a $770 \mathrm{~kg} / \mathrm{m}^{3}$, o que é esperado para espécies em áreas nativas.

Os valores médios de poder calorífico superior, encontrados neste trabalho, não diferiram entre classes diamétricas ao nível de 5\% de probabilidade para terra-firme. Apesar das idades e condições silviculturais distintas, entre os plantios a diferença foi de apenas $25 \mathrm{kcal} / \mathrm{kg}$, o que é irrelevante, pois segundo Brand (2010) para efeito prático de uso da biomassa para geração de energia são consideradas relevantes apenas diferenças superiores a $300 \mathrm{kcal} / \mathrm{kg}$.

Oliveira et al. (2008) encontraram valores de PCS de tachibranco cultivado em diferentes níveis de adubação que variaram entre $4.616 \mathrm{kcal} / \mathrm{kg}$ a $4.731 \mathrm{kcal} / \mathrm{kg}$, apresentando uma média de $4.671 \mathrm{kcal} / \mathrm{kg}$, superior ao encontrado nos dois plantios analisados neste trabalho.

A análise do teor de cinzas nos combustíveis de biomassa é imprescindível na avaliação energética desses materiais, uma vez que altos teores de cinza contribuem para a redução do poder calorífico visto que os materiais minerais não participam do processo de combustão (Paula et al., 2011; Protásio et al., 2011). Barros et al. (2012) afirmam que o maior poder calorífico está relacionado ao menor teor de cinzas, porém, segundo os mesmos autores, estes parâmetros podem estar associados à qualidade do solo, ou a capacidade de absorção de macro e micronutrientes. Neste trabalho não se observou relação significativa entre poder calorífico e teor de cinzas.

Alguns estudos de caracterização energética com tachibranco e outras espécies semelhantes apresentaram teores de materiais voláteis próximos ao encontrado neste trabalho. Nones et al. (2015) analisando a madeira de Eucalyptus benthamii, em duas idades, encontraram um valor médio de $82,1 \%$. Já Oliveira et al. (2008) em um experimento com tachibranco em diferentes níveis de adubação chegaram a um teor de material volátil de $83,8 \%$.

Quando se analisa a produção energética por hectare (Figura 6), a densidade populacional de indivíduos da classe 4 , torna a classe mais produtiva nos dois plantios, seguindo a tendência de produção de massa seca, por hectare, observada na Tabela 3. Esta ocorrência indica que, do ponto de vista da produtividade, e em caso de manejo destes povoamentos para a produção de energia, o corte das árvores deve ser feito quando as mesmas atingirem os diâmetros intermediários, mais especificamente o diâmetro entre 25 e $27 \mathrm{~cm}$.

No cerrado, a produtividade energética anual foi superior à terra-firme, em todas as classes. Isto se deve principalmente a diferença de idade entre os plantios. No caso de espécies nativas, sem melhoramento genético, ainda que em plantios experimentais, a idade mais elevada pode determinar maiores densidades básica na madeira e um maior incremento de biomassa seca ao longo dos anos, resultando em uma densidade energética maior. Oliveira et al. (2008) indicaram em seu estudo que o tachi-branco, com 18 anos de idade, ainda não atingiu sua maturidade quanto à densidade.

A densidade energética está relacionada à energia contida num determinado volume de madeira, por esse motivo a densidade energética foi significativamente influenciada pela densidade básica, nos dois plantios, como pode ser observado na Figura 8.

Outro fator a ser considerado condiz às estruturas dos plantios. O plantio de terra-firme localizava-se em área dentro de uma floresta ombrófila de terra-firme, caracterizada por árvores de grande e médio porte. Por outro lado, o plantio de cerrado sofreu efeito de borda por encontrar-se em área mais aberta, com maior exposição à radiação solar, podendo resultar em alterações na produção de biomassa e energia.

Neves et al. (2013) afirmaram que para produção de bioenergia, são recomendáveis maiores valores de densidade da madeira, uma vez que essa propriedade está relacionada à produtividade de massa seca e, consequentemente, de energia. Ainda, segundo os autores, quanto maior a densidade energética, maior a disponibilidade de energia por volume.

\section{CONCLUSÕES}

Em geral, os valores médios para densidade básica, cinzas, voláteis da madeira de Tachigali vulgaris, nos dois biomas, apresentaram-se satisfatórias visando ao uso para produção de energia.

$\mathrm{O}$ cerrado, devido à diferença de idade e ausência de competição, obteve um melhor desempenho na produção 
energética, com valores elevados de densidade energética, tanto individualmente, quanto por área.

Os resultados apresentados corroboram com o indicativo da aptidão energética desta espécie e reforçam a necessidade de estudos relacionados ao seu melhoramento genético para uso bioenergético.

Sugere-se o desenvolvimento de outros experimentos com árvores de tachi-branco, a partir de áreas nativas, para comparar o índice energético destas com os obtidos a partir dos plantios experimentais controlados. Dessa forma, podemse criar políticas de incentivo ao uso racional e eficiente da biomassa florestal, para produção de energia em assentamentos agrícolas.

\section{REFERÊNCIAS}

ABNT ASSOCIAÇÃO BRASILEIRA DE NORMAS TÉCNICAS. NBR 8633: Carvão vegetal: determinação do poder calorífico. Método de ensaio. Rio de Janeiro, 1984. $13 \mathrm{p}$.

ABNT_ASSOCIAÇÃO BRASILEIRA DE NORMAS TÉCNICAS. NBR 8112: Carvão vegetal: análise imediata. Método de ensaio. Rio de Janeiro, 1986. 5 p.

ABNT_ASSOCIAÇÃO BRASILEIRA DE NORMAS TÉCNICAS. NBR 7190: Projetos de estrutura de madeira. Rio de Janeiro, 1997. 107p.

BARROS, S. V. dos S.; NASCIMENTO, C. C. do; AZEVEDO, C. P. de. Caracterização tecnológica da madeira de três espécies florestais cultivadas no Amazonas: alternativa para produção de lenha. Floresta, Curitiba, v. 42, n. 4, p. 725-732, 2012. DOI: http://dx.doi.org/10.5380/rf.v42i4.22514

BRAND, M. A. Energia de biomassa florestal. 1. ed. Rio de Janeiro: Interciência, 2010. 131p.

CARVAlHO, P. E. R. Taxi-Branco - Taxonomia e nomenclatura. Colombo: Embrapa Florestas, 2005. 11p. (Circular técnica, 111)

CASTELO, P. A. R.; MATOS, J. L. M. de; DEDECEK, R. A.; LAVORANTI, O. J. Influência de diferentes sítios de crescimento sobre a qualidade da madeira de Pinus taeda. Floresta, Curitiba, v. 38, n. 3, p. 495-506, 2008. DOI: http://dx.doi.org/10.5380/rf.v38i3.12416

COSTA, T. G.; BIANCHI, M. L.; PROTÁSIO, T. P.; TRUGILHO, P. F.; PEREIRA, A. J. Qualidade da madeira de cinco espécies de ocorrência no cerrado para produção de carvão vegetal. Cerne, Lavras, v. 20, n. 1, p. 37-46, 2014. DOI: http://dx.doi.org/10.1590/S010477602014000100005

ELOY, E.; CARON, B. O.; SILVA, D. A. da.; SOUZA, V. Q. de.; TREVISAN, R.; BEHLING, A.; ELLI, E. F. Produtividade energética de espécies florestais em plantios de curta rotação. Ciência Rural, Santa Maria, v. 45, n. 8, p. 1424-1431, 2015. DOI: http://dx.doi.org/10.1590/0103$8478 \mathrm{cr} 20130177$

FARIAS, J.; MARIMON, B. S; SILVA, L. C. R.; PETTER, F. A.; ANDRADE, F. R.; MORANDI, P. S.; MARIMONJUNIOR, B. H. Survival and growth of native Tachigalivulgaris and exotic Eucalyptusurophylla Eucalyptus grandis trees in degraded soils with biochar amendment in southern Amazonia. Forest Ecologyand Management, Amsterdam, v. 368, p. 173-182, 2016. DOI: https://dx.doi.org/10.1016/j.foreco.2016.03.022

GONÇALVES, F. G.; LELIS R. C. C. Caracterização Tecnológica da Madeira de Acacia mangium Willd em
Plantio Consorciado com Eucalipto. Floresta e Ambiente, Seropédica, v. 3, n. 19, p. 286-295, 2012. DOI: http://dx.doi.org/10.4322/floram.2012.034

LIMA, E. A.; SILVA, H. D.; LAVORANTI, O. J. Caracterização dendroenergética de árvores Eucalyptus benthamii. Pesquisa Florestal Brasileira, Colombo, v. 31, n. 65, p. 09-17, 2011.

LIMA, H. C. Tachigali. LISTA de espécies da flora do Brasil 2012. Jardim Botânico do Rio de Janeiro, 2012. Disponível em: <http://floradobrasil.jbrj.gov.br/2012/FB100914>. Acesso em: 12 de maio de 2014.

MELOTTO, A.; NICODEMO, N. L.; BOCCHESE, R. A.; LAURA, V. A.; GONJITO NETO, M. M.; SCHLEDER, D. D.; POTT, A.; SILVA, V. P da. Sobrevivência e crescimento inicial em campo de espécies florestais nativas do brasil central indicadas para sistemas Silvipastoris. Revista Árvore, Viçosa, v. 33, n. 3, p. $425-$ 432, 2009. DOI: http://dx.doi.org/10.1590/S010067622009000300004

NEVES, T. A.; PROTÁSIO, T. P.; TRUGILlO, P. F.; VALLE, M. L. A.; SOUSA, L. C.; VIEIRA, C. M. M. Qualidade da madeira de clones de Eucalyptus em diferentes idades para a produção de bioenergia. Revista Ciências Agrarias, Belém, v. 56, n. 2, p. 139-148, 2013. DOI: http://dx.doi.org/10.4322/rca.2013.022

NONES, D. L.; BRAND, M. A.; CUNHA, A. B. da; CARVALHO, A. F. de; WEISE, S. M. K. Determinação das propriedades energéticas da madeira e do carvão vegetal produzido a partir de Eucalyptus benthamii. FLORESTA, Curitiba, v. 45, n. 1, p. 57-64, 2015. DOI: http://dx.doi.org/10.5380/rf.v45i1.30157

OLIVEIRA, I. R. M.; VALE, A. T.; MELO, J. T.; COSTA, A. F.; GONÇALEZ, J. C. Biomassa e características da madeira de Sclerolobium paniculatum cultivado em diferentes níveis de adubação. Cerne, Lavras, v. 14, n. 4, p. 351-357, 2008.

PAULA, L. E. R.; TRUGILHO, P. F.; NAPOLI, A.; BIANCHI, M. L. Characterization of residues from plant biomass for use in energy generation. Cerne, v. 17, n. 2, p. 237-246, 2011. DOI: http://dx.doi.org/10.1590/S010477602011000200012

PÉREZ, S.; RENEDO, C. J.; ORTIZ, A.; DELGADO, F.; FERNÁNDEZ, I. Energy potential of native shrub species in northern Spain. Renewable Energy, Philadelphia, v. 62, p. 79-83, 2014. DOI: https://dx.doi.org/10.1016/j.renene.2013.06.048

PROTÁSIO, T. P.; BUFALINO, L.; TONOLI, G. H. D.; COUTO, A. M.; TRUGILHO, P. F.; GUIMARÃES JÚNIOR, M. Relação entre o poder calorífico superior e os componentes elementares e minerais da biomassa vegetal. Pesquisa Florestal Brasileira, Colombo, v. 31, n. 66, p. 113-122, 2011.

DOI: http://dx.doi.org/10.4336/2011.pfb.31.66.113

RIBEIRO, A. O.; MENDES, L. M.; MORI, F. A.; ZIECH, R. Q. S.; MENDES, R. F. Variação da densidade básica da madeira de Toonaciliata Roem cultivada em diferentes localidades. Scientia Forestalis, Piracicaba, v. 39, n. 91, p. 359-366, 2011

SCOLFORO, J. R. S.; MELLO, J. M. Inventário florestal. Lavras: UFLA/FAEPE, 2006. 561 p.

SOUSA, V. G.; BRIENZA JÚNIOR, S.; BARBOSA, M. G.; MARTORANO, L. G.; SILVA, V. C. Taxi-branco (Tachigali vulgaris L. F. Gomes da Silva \& H.C. Lima): 
botânica, ecologia e silvicultura. Belém: Embrapa Amazônia Oriental, 2016. 37p.

STALLBAUN, P. H.; BARAÚNA, E. E. P.; MONTEIRO, T C.; VIEIRA, R. da S.; SALES, N. de L. P.; OLIVEIRA, L. S. Resistência natural da madeira de Tachigali vulgaris ao fungo xilófago Postia placenta. Pesquisa Florestal Brasileira, Colombo, v.36, n.88, p.459-463, 2016. DOI: http://dx.doi.org/10.4336/2016.pfb.36.88.1231.

THOMPSON, R. M. Estimativas de volume, biomassa e carbono para o carvoeiro (Sclerolobium paniculatum) vog. Var. SubvelutinumBenth). 2009. 64p. Dissertação (Mestrado em Ciências Florestais) - Universidade de Brasília, Brasília, 2009.

VIDAL, A. C. F; HORA, A. B. Perspectivas do setor de biomassa de madeira para geração de energia. BNDES Setorial, Rio de Janeiro, n. 33, p. 261-314, 2011.

ZANUNCIO, A. J. V.; LIMA, J. T.; MONTEIRO, T. C.; CARVAlHO, A. G.; TRUGILHO, P. F. Secagem de toras de Eucalyptus e Corymbia para uso energético. Scientia Forestalis, Piracicaba, v. 41, n. 99, p. 353-360, set. 2013. 